\title{
Biologic medicine inclusion in 138 national essential medicines lists
}

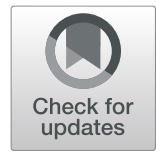

\author{
Raphaël Kraus ${ }^{1,2^{*}}$, Rae S. M. Yeung ${ }^{2,3}$ and Nav Persaud ${ }^{4}$ [D
}

\begin{abstract}
Background: Essential medicines lists (EMLs) are intended to reflect the priority health care needs of populations. We hypothesized that biologic disease-modifying antirheumatic drugs (DMARDs) are underrepresented relative to conventional DMARDs in existing national EMLs. We aimed to survey the extent to which biologic DMARDs are included in EMLS, to determine country characteristics contributing to their inclusion or absence, and to contrast this with conventional DMARD therapies.

Methods: We searched 138 national EMLs for 10 conventional and 14 biologic DMARDs used in the treatment of childhood rheumatologic diseases. Via regression modelling, we determined country characteristics accounting for differences in medicine inclusion between national EMLs.
\end{abstract}

Results: Eleven countries (7.97\%) included all 10 conventional DMARDs, 115 (83.33\%) $\geq 5$, and all countries listed at least one. Gross domestic product (GDP) per capita was associated with the total number of conventional DMARDs included $\left(\beta_{1} 1.02\right.$ [95\% Cl 0.39, 1.66]; $\left.P=0.00279\right)$. Among biologic DMARDs, 3 countries (2.2\%) listed $\geq 10,15(10.9 \%)$ listed $\geq 5$, and 47 (34.1\%) listed at least one. Ninety-one (65.9\%) of countries listed no biologic DMARDs. European region $\left(\beta_{1} 1.30[95 \% \mathrm{Cl} 0.08,2.52] ; P=0.0367\right)$, life expectancy $\left(\beta_{1}-0.70[95 \% \mathrm{Cl}-1.22,-0.18] ; P=0.0085\right)$, health expenditure per capita $\left(\beta_{1} 1.83\right.$ [95\% Cl 1.24, 2.42]; $\left.P<0.001\right)$, and conventional DMARDs listed $\left(\beta_{1} 0.70[95 \% \mathrm{Cl} 0.33\right.$, $1.07] ; P<0.001)$ were associated with the total number of biologic DMARDs included.

Conclusion: Biologic DMARDs are excluded from most national EMLs. By comparison, conventional DMARDs are widely included. Countries with higher health spending and longer life expectancy are more likely to list biologics.

Keywords: World Health Organization, Essential medicines lists, Disease-modifying antirheumatic drugs (DMARDs), Biologics, Rare disease, Pediatrics

\section{Background}

Rare diseases, by definition affecting small numbers of people relative to the general population (varying thresholds of maximal prevalence range from 5 to 76 per $100,000)$ and associated with specific issues relating to their rarity, represent an ever-growing subset of illness

\footnotetext{
* Correspondence: raphael.kraus@sickkids.ca

This article does not contain any studies with human or animal subjects performed by any of the authors.

'Department of Pediatrics, University of Toronto, Toronto, Canada

${ }^{2}$ Division of Rheumatology, Hospital for Sick Children, Toronto, Canada

Full list of author information is available at the end of the article
}

globally [1-3]. Recently, 6172 unique rare diseases were identified with an pooled global point prevalence of 3.5$5.9 \%$, translating to $263-446$ million affected persons worldwide [3]. More than half of rare diseases manifest in childhood with potentially disabling or even fatal consequence $[2,3]$. All pediatric-onset rheumatologic conditions can be considered rare. Juvenile idiopathic arthritis (JIA), the most common rheumatologic disease in children, has a pooled prevalence of 45 per 100,000 [4, 5]. We employ JIA as a prototype for childhood rheumatologic disease, which broadly encompasses JIA, systemic lupus erythematosus (SLE), Sjögren syndrome, idiopathic inflammatory myopathies (namely juvenile dermatomyositis,

(c) The Author(s). 2021 Open Access This article is licensed under a Creative Commons Attribution 4.0 International License, which permits use, sharing, adaptation, distribution and reproduction in any medium or format, as long as you give appropriate credit to the original author(s) and the source, provide a link to the Creative Commons licence, and indicate if changes were made. The images or other third party material in this article are included in the article's Creative Commons licence, unless indicated otherwise in a credit line to the material. If material is not included in the article's Creative Commons licence and your intended use is not permitted by statutory regulation or exceeds the permitted use, you will need to obtain permission directly from the copyright holder. To view a copy of this licence, visit http://creativecommons.org/licenses/by/4.0/ The Creative Commons Public Domain Dedication waiver (http://creativecommons.org/publicdomain/zero/1.0/) applies to the data made available in this article, unless otherwise stated in a credit line to the data. 
or JDM), systemic and localized sclerodermas, systemic vasculitides, sarcoidosis, and autoinflammatory syndromes (among others).

Historically, conventional disease-modifying antirheumatic drugs (DMARDs) have provided the basis for therapy of pediatric systemic inflammatory disease. The advent of targeted biologic DMARD therapies has spurred a paradigm shift in the disease outcomes, patient experience, and prognosis of JIA and other rheumatologic conditions. Outcomes have improved dramatically resulting in increased survival and quality of life [6]. Additionally, biologic DMARD therapies-although costly-may be cost-effective in childhood rheumatologic disease: tumor necrosis factor (TNF) inhibitors for the treatment of JIA and JIA-associated uveitis, for example, are potentially cost-effective from a health payer perspective $[7,8]$. Regulatory approval and public funding of drugs is typically dependent on support from randomized clinical trials allowing for cost-effectiveness analyses. In rare conditions, however, such data are limited or non-existent [9]. Thus, as biologic DMARDs are increasingly employed with life-changing effect, gaps in both public and private drug funding are exposed.

The World Health Organization (WHO) developed the Model list of essential medicines (WHO EML) "intended to meet the priority health care needs of a population" in 1977, an influential template since adapted by countries worldwide [10]. Subsequently, the WHO released a model list specifically delineating essential medicines for children (WHO EMLc) [11]. These essential medicines lists (EMLs) to guide countries' selection of drugs to fund, stock, prescribe, and dispense $[12,13]$. The Lancet Commission, "Essential medicines for universal health coverage," affirms that countries "must implement a comprehensive set of policies to achieve affordable prices ..." and equity in access [13]. A unique database of 138 national EMLs (71\% of 195 countries) and associated country characteristics was recently compiled and demonstrates significant variation between countries in included medicines [12, 13]. We hypothesized that biologic DMARDs are underrepresented relative to conventional DMARDs in the model WHO and existing national EMLs. We therefore aimed to survey the extent to which biologic medications with primary applications in childhood inflammatory disease are included in EMLs globally, to determine country characteristics contributing to their inclusion or absence, and to contrast this with conventional DMARD therapies.

\section{Methods}

\section{Data collection processes}

We made use of a previously compiled database (initially constructed in June 2017, most recently updated in
January 2020). To briefly summarize the initial data collection processes:

The WHO essential medicines and health products information portal, an online repository of publications of medicines and health products relevant to WHO priorities, was searched for updated versions of national EMLs. All EMLs were included irrespective of publication date and language. A data extraction method was then developed to query specific medicines within these compiled lists (from each country's EML, medicines were manually extracted using International Nonproprietary Names). Country characteristics (WHO region; population size; life expectancy; infant mortality; gross domestic product [GDP] per capita; health care expenditure per capita; Gini index as a measure of income inequality; and the corruption perception index) were collected. Note that national EMLs include medicines for both adults and children and listing decisions may be related to total population; therefore, we collected total rather than pediatric population data. Details of the sources of these characteristics are outlined in the original publication [12].

Although the initial database construction accounted for potential redundancies in medicines (i.e. medicines considered therapeutically equivalent), this was not relevant to our analysis, as we queried only specific medicines with well-established applications in pediatric systemic inflammatory disease as below.

\section{Selection of medicines of interest}

We sought to include all systemic biologic and conventional DMARDs in routine clinical use for the treatment of JIA, SLE, JDM, scleroderma, systemic vasculitides, and autoinflammatory disorders. We supported the selection of medicines by relevant clinical guidelines as cited below (pediatric-specific guidelines are referenced when available; note that many medicines employed in pediatric rheumatology settings are not supported by pediatric-specific clinical trials and are therefore administered "off-label"). We excluded certain novel medicines (e.g., Janus kinase [JAK] inhibitors) given their limited clinical use (Table 1).

\section{Data analysis}

For descriptive data, we calculated medians with interquartile ranges (IQRs).

\section{Comparison between countries}

To determine whether country characteristics accounted for differences in medicine inclusion between countries, we created a linear regression model with the total number of included medicines as the dependent variable and the following characteristics as independent variables: WHO region, population size, life expectancy, GDP per 
capita, and health expenditure per capita. We fitted separate regression models for biologic and conventional DMARDs. In addition to the above variables, we included the number of conventional DMARDs on a country's EML ("conventional DMARDs listed") as a regressor in the analysis of biologic DMARDs. Adjusted $R^{2}$ values for the number of independent variables are also presented. Analysis was completed using $\mathrm{R}$ statistical package (R Foundation, Vienna, Austria).

\section{Data sharing}

The underlying data used in this study are publicly available and, separately, a database with updated information about national EMLs is maintained online [14].

\section{ethics approval}

No ethics approval was sought for this review of publicly available information.

\section{Results}

The 138 national EMLs (of 195 total countries; 71\%) published between 2001 and 2017 have between 44 and 980 medicines listed (median 308, mean 366.9).

\section{Conventional DMARDs}

We examined a total of 10 conventional DMARDs (or classes of medicines). As shown in Table 2, the most commonly listed conventional DMARD was corticosteroids, present on $100 \%$ of EMLs. Five countries (Angola, Cambodia, Djibouti, Somalia, and South Africa) list only corticosteroids and no other conventional DMARDs. Country-specific details are presented in the supplementary appendix. The least commonly listed conventional agent was leflunomide (21.74\% of countries). Along with colchicine, mycophenolic acid, and sulfasalazine, leflunomide was not included in the WHO model list. The lone difference in included conventional DMARDs between the WHO EML and EMLc is the inclusion of sulfasalazine in the former. Eleven countries (7.97\%) included all 10 conventional medicines of interest, while 115 $(83.33 \%) \geq 5$. All countries listed at least one. The number of conventional DMARDs included ranged from 1 to 10 (median 7; IQR 5 to 8; mean 6.565).

The multivariate linear regression indicated that the 5 included country characteristics accounted for a third of the observed differences in number of included conventional DMARDs between countries' lists (adjusted $\left.R^{2}: 0.33\right)$. GDP per capita $\left(\beta_{1} 1.02\right.$ [95\% CI $0.39,1.66] ; P=0.00279)$ was significantly associated with the total number of medicines included. Life expectancy $\left(\beta_{1} 0.56[95 \%\right.$ CI $\left.0.00,1.12] ; P=0.05174\right)$ approached statistical significance.
Table 1 Selected medicines of interest

\begin{tabular}{l} 
Conventional DMARDs medicines (alphabetical) \\
Azathioprine [29-33] \\
Calcineurin inhibitors (cyclosporine, pimecrolimus, tacrolimus considered \\
together) [29, 34-39] \\
Colchicine [40] \\
Corticosteroids (cortisone, dexamethasone, hydrocortisone, \\
methylprednisolone, prednisone, triamcinolone considered together) \\
[29-35, 38, 39, 41-50] \\
Cyclophosphamide [30-33, 36-39] \\
Hydroxychloroquine [36, 37] \\
Leflunomide [29, 30, 32, 34, 35, 41, 42] \\
Methotrexate [29, 31-36, 38, 41-43, 45-47, 50-52] \\
Mycophenolate mofetil and mycophenolate sodium considered \\
together [29, 31-38, 44, 47, 51, 52] \\
Sulfasalazine [29, 41, 42] \\
Biologic DMARDs (alphabetical) \\
Abatacept [29, 34, 35, 41, 42] \\
Adalimumab [34, 35, 41, 42] \\
Anakinra [39, 43, 49] \\
Belimumab [36] \\
Canakinumab [49] \\
Certolizumab [42] \\
Etanercept [34, 38, 41, 42, 49, 50] \\
Golimumab [29, 35, 41, 42] \\
Infliximab [29, 34, 35, 38, 39, 41, 42, 48, 50] \\
Rilonacept [49] \\
Rituximab [29, 31, 33, 35, 36, 41, 42, 52] \\
Tocilizumab [29, 32-35, 41-43, 49] \\
Ustekinumab [53, 54] \\
\hline
\end{tabular}

\section{Biologic DMARDs}

We examined a total of 14 biologic DMARDs. As depicted in Table 3, the most commonly listed biologic agent was rituximab, listed by 42 countries (30.43\%). Adalimumab, certolizumab, etanercept, golimumab, infliximab, and rituximab were included on the WHO EML, while only adalimumab, etanercept, infliximab, and rituximab were included on the EMLc. The least commonly listed biologics were the newer agents belimumab and canakinumab (listed by two countries [1.45\%] each). As depicted in Fig. 1, Slovenia listed the greatest number of biologics at 13, while its geographic neighbors Slovakia and the Czech Republic listed 12 and 11 , respectively. Thus, three countries (2.2\%) listed $\geq 10$ biologics; 15 (10.9\%) were found to list $\geq 5$, while 47 (34.1\%) listed at least one biologic. Ninety-one (65.9\%) of countries listed zero. The number of biologic agents included ranged from 0 to 13 (median 0 ; IQR 0 to 1 ; 
Table 2 Inclusion of conventional non-biologic medicines in the WHO Model List and national essential medicines lists

\begin{tabular}{|c|c|c|c|}
\hline $\begin{array}{l}\text { Conventional non- } \\
\text { biologic medicine of } \\
\text { interest }\end{array}$ & $\begin{array}{l}\text { Inclusion in } 2019 \text { WHO Model List } \\
\text { of Essential Medicines (Yes/No) }\end{array}$ & $\begin{array}{l}\text { Inclusion in } 2019 \text { WHO Model List of } \\
\text { Essential Medicines for Children (Yes/No) }\end{array}$ & $\begin{array}{l}\text { Total number of countries listing } \\
\text { conventional medicine of } \\
\text { interest (\%) }\end{array}$ \\
\hline Azathioprine & Yes & Yes & $108(78.26)$ \\
\hline Calcineurin Inhibitors & Yes & Yes & $91(65.94)$ \\
\hline Colchicine & No & No & $88(63.77)$ \\
\hline Corticosteroids & Yes & Yes & $138(100)$ \\
\hline Cyclophosphamide & Yes & Yes & 115 (83.33) \\
\hline Hydroxychloroquine & Yes & Yes & $58(42.03)$ \\
\hline Leflunomide & No & No & $30(21.74)$ \\
\hline Methotrexate & Yes & Yes & $127(92.03)$ \\
\hline $\begin{array}{l}\text { Mycophenolic acid } \\
\text { (Mycophenolate) }\end{array}$ & No & No & 55 (39.86) \\
\hline $\begin{array}{l}\text { Sulfasalazine } \\
\text { (Salazosulfapyridine) }\end{array}$ & Yes & No & $96(69.57)$ \\
\hline
\end{tabular}

mean 1.239). Notably, data is unavailable for Canada and United States, among others.

The multivariate linear regression revealed that the six included country characteristics accounted for greater than half of the observed differences in number of included biologic DMARDs between countries' lists (adjusted $\left.R^{2}: 0.55\right)$. As demonstrated in Fig. 2, European region $\left(\beta_{1} 1.30\right.$ [95\% CI 0.08, 2.52]; $\left.P=0.0367\right)$, life expectancy $\left(\beta_{1}-0.70\right.$ [95\% CI $\left.\left.-1.22,-0.18\right] ; P=0.0085\right)$, health expenditure per capita $\left(\beta_{1} 1.83\right.$ [95\% CI 1.24, 2.42]; $P<0.001)$, and conventional DMARDs listed $\left(\beta_{1}\right.$ 0.70 [95\% CI $0.33,1.07] ; P<0.001)$ were significantly associated with the total number of biologic DMARDs included, the latter two with $P$ values approaching zero. The association between the number of conventional
DMARDs included and the number of biologic DMAR Ds included is most evident in the WHO regions of Eastern Mediterranean, Europe, and The Americas.

While health expenditure per capita was predictive of biologic inclusion and GDP per capita was not, post-hoc analysis (we re-applied the regression model without health care spending per capita and found GDP to be highly statistically significant) confirmed this to be due to collinearity.

\section{Discussion}

Biologic DMARDs with applications in childhood inflammatory disease are excluded from most national EMLs despite their potential to improve outcomes and reduce health care utilization in childhood rheumatologic

Table 3 Inclusion of biologic medicines in the WHO Model List and national essential medicines lists

\begin{tabular}{|c|c|c|c|}
\hline $\begin{array}{l}\text { Biologic } \\
\text { medicine of } \\
\text { interest }\end{array}$ & $\begin{array}{l}\text { Inclusion in } 2019 \text { WHO Model List of } \\
\text { Essential Medications (Yes/No) }\end{array}$ & $\begin{array}{l}\text { Inclusion in } 2019 \text { WHO Model List of } \\
\text { Essential Medicines for Children (Yes/No) }\end{array}$ & $\begin{array}{l}\text { Total number of countries listing } \\
\text { biologic medicine of interest (\%) }\end{array}$ \\
\hline Abatacept & No & No & $4(2.9)$ \\
\hline Adalimumab & Yes & Yes & $20(14.49)$ \\
\hline Alemtuzumab & No & No & $12(8.7)$ \\
\hline Anakinra & No & No & $5(3.62)$ \\
\hline Belimumab & No & No & $2(1.45)$ \\
\hline Canakinumab & No & No & $2(1.45)$ \\
\hline Certolizumab & Yes & No & $8(5.8)$ \\
\hline Eculizumab & No & No & $3(2.17)$ \\
\hline Etanercept & Yes & Yes & $28(20.29)$ \\
\hline Golimumab & Yes & No & $6(4.35)$ \\
\hline Infliximab & Yes & Yes & $22(15.94)$ \\
\hline Rituximab & Yes & Yes & $42(30.43)$ \\
\hline Tocilizumab & No & No & $11(7.97)$ \\
\hline Ustekinumab & No & No & $6(4.35)$ \\
\hline
\end{tabular}




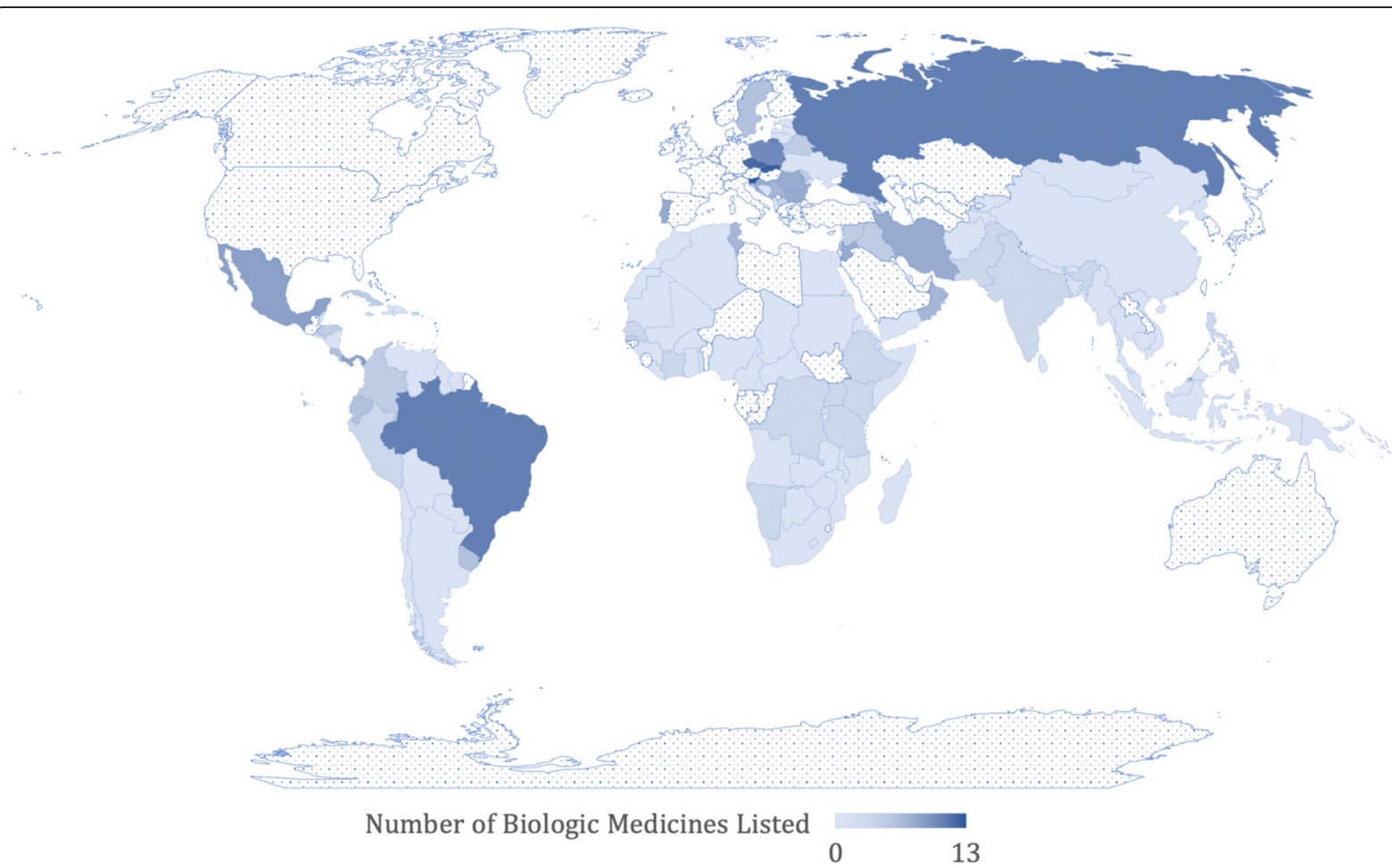

Fig. 1 Number of biologic medicines included in national essential medicines lists by country. Notes: The number of biologic agents included ranged from 0 to 13 . Countries for which no data are available are denoted by dotted pattern

illness. By comparison, conventional DMARDs, many used to treat both rheumatologic and other conditions, are widely included in national EMLs. Countries with higher health spending and longer life expectancy are more likely to list biologics. Rituximab is the most widely included biologic agent in national EMLs at greater than $30 \%$. Importantly, rituximab was the only biologic agent included in the 2017 version of the WHO EML; the 2019 iteration, however, introduced multiple TNF-inhibitors (adalimumab, certolizumab, etanercept, golimumab, infliximab), a reflection of the growing role of biologic therapies.

As might be expected, the two least commonly listed biologic DMARDs (canakinumab and belimumab, each listed by two countries) were included by countries with relatively expansive EMLs. Slovenia (total 13 biologics listed) included both canakinumab and belimumab, while the Czech Republic (which lists canakinumab) and Slovakia (which lists belimumab) each include 12 biologics in their respective EMLs.

To our knowledge, this is the first study to examine EML inclusion of medicines with primary applications in rare disease. This is of particular importance given their growing prevalence and associated costs to health systems [3]. The mean annual total cost of JIA, for example, is estimated between US\$5683.51 (US\$3637.90 in 1999) and US\$50,137.91 (US\$33,171 in 2000) [15]. The annualized average direct medical costs of JIA patients at two Canadian centers was found to be CAD\$2119 (CAD\$1686 in 2007) greater than those of healthy controls, the majority of this difference attributable to medication costs [16]. Overall, there exists a paucity of cost evidence in rare diseases-an opportunity for future research.

Strategies for EML development vary by country. In South Africa, for example, members of the National Essential Medicines List Committee (NEMLC) are appointed by the Minister of Health $(\mathrm{MOH})$ on the basis of clinical, pharmacologic, public health, health economic, and bioethical expertise [17]. The process begins with an evidence-based assessment of quality, safety, and efficacy, followed by formal pharmacoeconomic evaluation. The NEMLC is the decision-making body and presents the finalized EML to the $\mathrm{MOH}$ for implementation [17].

Treatments for cardiovascular disease are included in most national EMLs [18]. Many drugs for HIV-AIDS that, similar to biologics, are relatively costly are now classified as essential in the WHO model lists and are commonplace on national EMLs [13]. In contrast, the WHO EML and EMLc fail to adequately address the needs of children with rheumatologic disease and do not "reflect current best practice." [19, 20] Moreover, despite being included in the WHO model lists, the decades old and relatively inexpensive drug methotrexate-a first-line therapy for JIA-is conspicuously absent from nearly $10 \%$ 


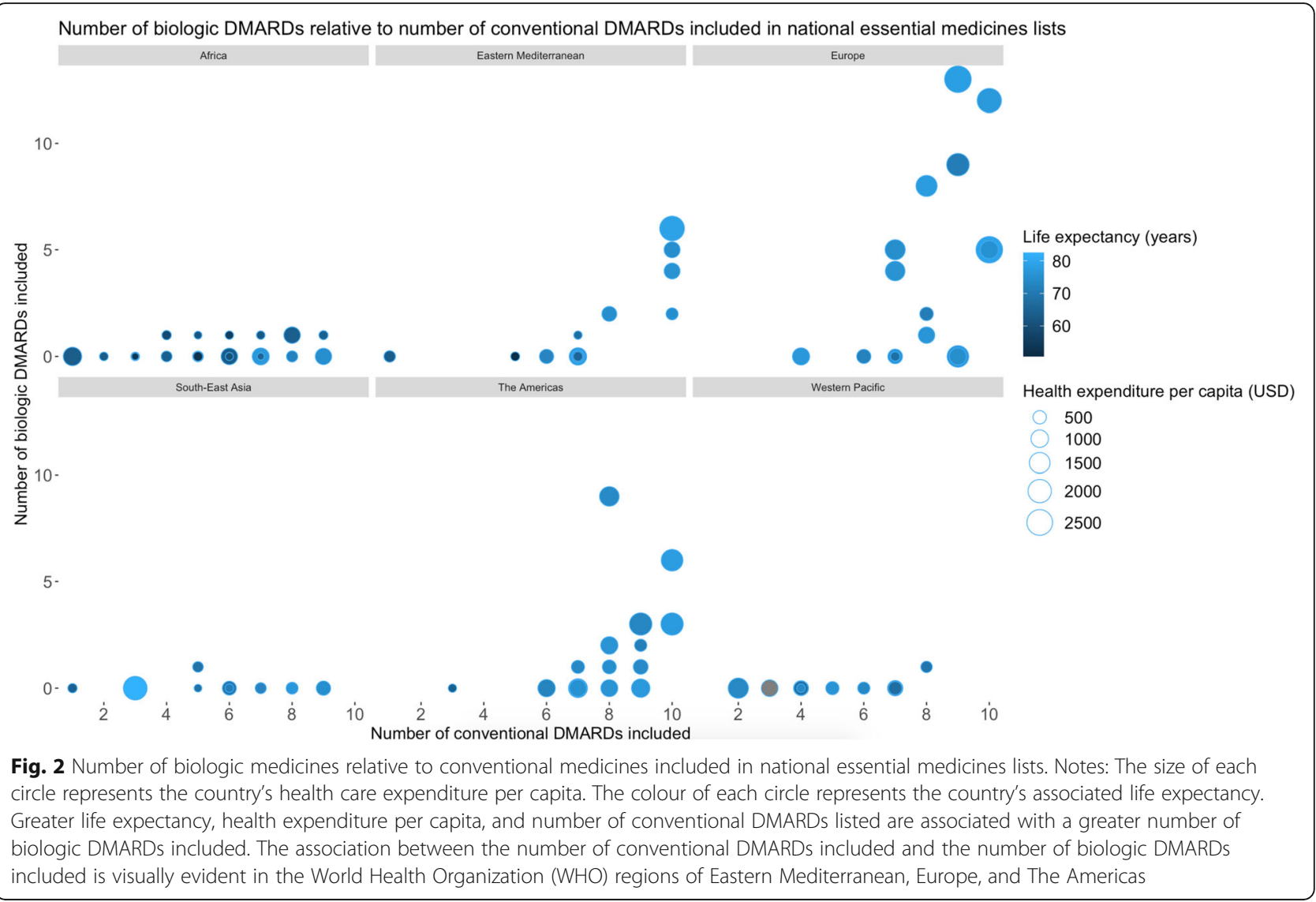

of EMLs. In a recent survey of Paediatric Global Musculoskeletal Health Task Force members, five medicines were deemed "essential" for inclusion in the WHO EML (oral, intraarticular, and intravenous corticosteroids; nonsteroidal anti-inflammatory drugs; hydroxychloroquine; and methotrexate), while many DMARDs-both conventional and biologic-"should" be listed [20]. Although the 2019 update of the WHO EML and EMLc partially addresses these deficiencies via the inclusion of TNF-inhibitors, further revision of the model lists is needed. Serving as influential templates for national EMLs, greater inclusion of biologics within the WHO EML and EMLc would likely improve access globally.

While a drug may be available (i.e., stocked, supplied, and dispensed) in a given country, it may not be readily accessible as a result of prohibitive costs and reimbursement policies. Access to biologic DMARDs varies between countries, resulting in discrepant health outcomes. In rheumatoid arthritis, between-country differences in GDP per capita, drug reimbursement rules, and affordability of biologics influence biologic usage and measures of disease activity, suggesting geographic inequities in access to optimal care [21]. In JIA, children living in countries with lower GDP suffer greater disease activity and damage, likely in part due to disparities in access to biologic therapies [22]. The inclusion of medications in EMLs has been shown to decrease their cost, increase availability, and improve patient outcomes over time [23, 24]. Using a model list of essential medicines for Canada, the potential savings yielded from universal public coverage of these drugs is estimated over CAD\$4 billion per year for patients and private drug plan sponsors [23]. It is reasonable to extrapolate that the inclusion of biologic therapies in national EMLs and, ultimately, systems of universal prescription drug coverage would abate the economic impact and improve the quality of life of children with systemic inflammatory disease.

Our study has limitations. EML data was abstracted from the WHO website in a procedure liable to error (e.g., documents requiring translation, inconsistencies in medicine names) [12]. Next, many developed nations (namely Canada, the United States, the United Kingdom, much of Western Europe, Australia, New Zealand, Japan) do not have national EMLs. The inclusion of such high-income countries would likely not change our finding that higher health spending is associated with the listing of biologic DMARDs. Additionally, with the continued emergence of novel biologic therapies, we exluded a number of molecules with relevance in 
pediatric rheumatology (e.g., JAK inhibitors) from our analysis. Also, while health workforce characteristics (e.g., pediatric rheumatologists per capita) may influence medicine inclusion in EMLs, we did not have reliable workforce data for all included countries. Lastly, we note that the listing of a drug on an EML does not necessarily imply that it is available to that nation's public; conversely, a drug may be available despite being absent from an EML. While EMLs serve to guide the supply and reimbursement of medicines, the choice of which drugs to fund, stock, prescribe, and dispense ultimately belongs to local governments, health systems, and insurers [10, 25]. Moreover, many medicines in routine clinical use for the treatment of pediatric rheumatologic conditions are administered "off-label" and their inclusion in national EMLs may be primarily motivated by alternate therapeutic indications (e.g., rituximab for hematologic malignancy) $[11,26]$. The data are therefore interpreted with appropriate caution.

\section{Conclusion}

Although biologic DMARDs are underrepresented in national EMLs and are more likely to be listed by highincome countries, this does not preclude their inclusion by less prosperous nations. For example, only nine of the 42 countries $(21.4 \%)$ listing rituximab (the most commonly listed biologic) are categorized as highincome; 33 of $42(78.6 \%)$ are therefore low- or middleincome economies [27]. This indicates the potential for other countries to consider the listing of biologic DMAR Ds, which would ultimately lead to a lowering of their costs and a resultant increase in their cost-effectiveness, thus rendering them more attractive to governmental and other health payers. Costs to health payers are likely to further decrease with the growth of the biosimilar market, driving price competition and improved patient access to biologic therapies [28]. The inclusion of these medicines in a system of universal prescription drug coverage would ultimately abate the economic impact and improve the quality of life of children with systemic inflammatory disease. Further study of the real-world availability and accessibility of biologic DMARDs is needed.

\section{Abbreviations \\ DMARD: Disease-modifying antirheumatic drug; EML: Essential medicines list; GDP: Gross domestic product; JAK: Janus kinase; JDM: Juvenile dermatomyositis; JIA: Juvenile idiopathic arthritis; SLE: Systemic lupus erythematosus; WHO: World Health Organization}

\section{Supplementary Information}

The online version contains supplementary material available at https://doi. org/10.1186/s12969-021-00608-Z

Additional file 1.

\section{Acknowledgements}

Not applicable.

\section{Authors' contributions}

RK participated in study design, literature search, data collection, data analysis and interpretation, manuscript writing, review and approval of final manuscript. RSMY participated in study design, literature search, data interpretation, review and approval of final manuscript. NP participated in study design, literature search, data collection, data analysis and interpretation, manuscript writing, review and approval of final manuscript.

\section{Funding}

No specific funding was received from any bodies in the public, commercial or not-for-profit sectors to carry out the work described in this article.

\section{Availability of data and materials}

The datasets used and/or analysed during the current study are available from the corresponding author on reasonable request.

\section{Declarations}

Ethics approval and consent to participate

Not applicable.

Consent for publication

Not applicable.

\section{Competing interests}

RK has no acknowledgments nor competing interests to disclose. RSMY is supported by the Hak-Ming and Deborah Chiu Chair in Paediatric Translational Research at the Hospital for Sick Children, University of Toronto and has participated as a consultant for Novartis and Lily and in clinical trials sponsored by Roche. NP reports grants from Canadian Institutes of Health Research and the Ontario SPOR Support Unit outside of the submitted work.

\section{Author details}

${ }^{1}$ Department of Pediatrics, University of Toronto, Toronto, Canada. ${ }^{2}$ Division of Rheumatology, Hospital for Sick Children, Toronto, Canada. ${ }^{3}$ Departments of Pediatrics, Immunology and Medical Science, University of Toronto, Toronto, Canada. ${ }^{4}$ Department of Family and Community Medicine, St. Michael's Hospital, University of Toronto, Toronto, Canada.

Received: 9 March 2021 Accepted: 31 May 2021

Published online: 06 September 2021

\section{References}

1. Orphanet. The Portal for Rare Diseases and Orphan Drugs. About Rare Diseases [Internet]. 2017; [cited 2020 Aug 19]. Available from: http://www. orpha.net/national/CA-EN/index/about-rare-diseases/.

2. Lee DK, Wong B. An orphan drug framework (ODF) for Canada. J Popul Ther Clin Pharmacol. 2014;21(1):42-6.

3. Nquengang Wakap S, Lambert DM, Olry A, Rodwell C, Gueydan C, Lanneau $V$, et al. Estimating cumulative point prevalence of rare diseases: analysis of the Orphanet database. Eur J Hum Genet [Internet]. 2020;28(2):165-73 Available from: http://dx.doi.org/10.1038/s41431-019-0508-0.

4. Ramanan AV, Dick AD, Jones AP, McKay A, Williamson PR, CompeyrotLacassagne $\mathrm{S}$, et al. Adalimumab plus methotrexate for uveitis in juvenile idiopathic arthritis. N Engl J Med. 2017;376(17):1637-46. https://doi.org/10.1 056/NEJMoa1614160.

5. Thierry S, Fautrel B, Lemelle I, Guillemin F. Prevalence and incidence of juvenile idiopathic arthritis: a systematic review. Jt Bone Spine. 2014;81(2): 112-7. https://doi.org/10.1016/j.jbspin.2013.09.003.

6. Sterba $\mathrm{Y}$, llowite N. Biologics in pediatric rheumatology: quo vadis? Curr Rheumatol Rep. 2016;18(7):45. https://doi.org/10.1007/s11926-016-0593-9.

7. Ungar WJ, Costa V, Hancock-Howard R, Feldman BM, Laxer RM. Costeffectiveness of biologics in polyarticular-course juvenile idiopathic arthritis patients unresponsive to disease-modifying antirheumatic drugs. Arthritis Care Res. 2011;63(1):111-9. https://doi.org/10.1002/acr.20337.

8. Luca NJ, Burnett HF, Ungar WJ, Moretti ME, Beukelman T, Feldman BM, et al. Cost-effectiveness analysis of first-line treatment with biologic agents in 
Polyarticular juvenile idiopathic arthritis. Arthritis Care Res. 2016;68(12):180311. https://doi.org/10.1002/acr.22903.

9. Winquist E, Bell CM, Clarke JTR, Evans G, Martin J, Sabharwal M, et al. An evaluation framework for funding drugs for rare diseases. Value Heal [Internet]. 2012;15(6):982-6 Available from: http://dx.doi.org/10.1016/j.jval.2012.06.009.

10. World Health Organization. Essential medicines and health products [Internet]. 2020 [cited 2020 Aug 20]. Available from: https://www.who.int/ medicines/services/essmedicines_def/en/

11. World Health Organization. World Health Organization Model List of Essential Medicines for Children 7th List. Report. 2019:(7th List):1-42.

12. Persaud N, Jiang M, Shaikh R, Bali A, Oronsaye E, Woods H, et al. Comparison of essential medicines lists in 137 countries. Bull World Health Organ. 2019;97(6):394-404C. https://doi.org/10.2471/BLT.18.222448.

13. Wirtz VJ, Hogerzeil HV, Gray AL, Bigdeli M, de Joncheere CP, Ewen MA, et al. Essential medicines for universal health coverage. Lancet. 2017;389(10067): 403-76. https://doi.org/10.1016/S0140-6736(16)31599-9.

14. EMLs Around The World [Internet]. [cited 2020 Aug 20]. Available from: https://global.essentialmeds.org/dashboard/countries

15. Angelis A, Tordrup D, Kanavos P. Socio-economic burden of rare diseases: A systematic review of cost of illness evidence. Health Policy (New York) [Internet]. 2015;119(7):964-79 Available from: http://dx.doi.org/10.1016/j. healthpol.2014.12.016.

16. Bernatsky S, Duffy C, Malleson P, Feldman DE, St. Pierre Y, Clarke AE. Economic impact of juvenile idiopathic arthritis. Arthritis Care Res Off J Am Coll Rheumatol. 2007;57(1):44-8. https://doi.org/10.1002/art.22463.

17. Perumal-Pillay VA, Suleman F. Selection of essential medicines for South Africa-an analysis of in-depth interviews with national essential medicines list committee members. BMC Health Serv Res. 2017;17(1):1-17.

18. Jarvis JD, Woods H, Bali A, Oronsaye E, Persaud N. Selection of WHOrecommended essential medicines for non-communicable diseases on National Essential Medicines Lists. PLoS One. 2019;14(8):1-15.

19. Foster HE, Scott C. Update the WHO EML to improve global paediatric rheumatology. Nat Rev Rheumatol. 2020;16(3):123. https://doi.org/10.1038/ s41584-020-0368-6.

20. Scott C, Smith N, James R, Whitehead B, Green R, Foster HE. Revising the WHO essential medicines list for paediatric rheumatology. Pediatr Rheumatol. 2021;19(1):1-2.

21. Bergstra SA, Branco JC, Vega-Morales D, Salomon-Escoto K, Govind N, Allaart $C F$, et al. Inequity in access to bDMARD care and how it influences disease outcomes across countries worldwide: results from the METEOR-registry. Ann Rheum Dis. 2018;77(10):1413-20. https://doi.org/10.1136/a nnrheumdis-2018-213289.

22. Consolaro A, Giancane G, Alongi A, van Dijkhuizen EHP, Aggarwal A, AlMayouf SM, et al. Phenotypic variability and disparities in treatment and outcomes of childhood arthritis throughout the world: an observational cohort study. Lancet Child Adolesc Heal. 2019;3(4):255-63. https://doi.org/1 0.1016/S2352-4642(19)30027-6.

23. Morgan SG, Li W, Yau B, Persaud N. Estimated effects of adding universal public coverage of an essential medicines list to existing public drug plans in Canada. Cmaj. 2017;189(8):E295-302. https://doi.org/10.1503/cmaj.161082.

24. Bazargani YT, Ewen M, De Boer A, Leufkens HGM, Mantel-Teeuwisse AK. Essential medicines are more available than other medicines around the globe. PLoS One. 2014;9(2):1-7.

25. Kar SS, Pradhan HS, Mohanta GP. Concept of essential medicines and rational use in public health. Indian J community Med Off Publ Indian Assoc Prev Soc Med. 2010;35(1):10.

26. Organización Mundial de la Salud (OMS). World health organization model list of essential medicines. Ment Holist Heal Some Int Perspect. 2019;21:119-34.

27. Team WBD. New country classifications by income level: 2019-2020 [Internet]. World Bank Blogs. 2019; [cited 2020 Nov 4]. Available from: https://blogs.worldbank.org/opendata/new-country-classifications-incomelevel-2019-2020.

28. Kent D, Rickwood S, Di Biase S. Disruption and maturity: the next phase of biologics [internet]. QuintilesIMS. 2017; Available from: https://www.iqvia. com/-/media/iqvia/pdfs/nemea/uk/disruption_and_maturity_the_next_pha se_of_biologics.pdf.

29. Constantin T, Foeldvari I, Anton J, De Boer J, Czitrom-Guillaume S, Edelsten C, et al. Consensus-based recommendations for the management of uveitis associated with juvenile idiopathic arthritis: the SHARE initiative. Ann Rheum Dis. 2018;77(8):1107-17.
30. McGeoch L, Twilt M, Famorca L, Bakowsky V, Barra L, Benseler S, et al. CanVasc recommendations for the management of antineutrophil cytoplasm antibody (ANCA)-associated vasculitides - Executive summary. Can J Kidney Heal Dis [Internet]. 2015;2(1):1-6 Available from: http://dx.doi. org/10.1186/s40697-015-0078-1.

31. Yates M, Watts RA, Bajema IM, Cid MC, Crestani B, Hauser T, et al. EULAR/ ERA-EDTA recommendations for the management of ANCA-associated vasculitis. Ann Rheum Dis. 2016;75(9):1583-94.

32. Hellmich B, Agueda A, Monti S, Buttgereit F, De Boysson H, Brouwer E, et al. 2018 Update of the EULAR recommendations for the management of large vessel vasculitis. Ann Rheum Dis. 2020;79(1):19-30.

33. de Graeff N, Groot N, Brogan P, Ozen S, Avcin T, Bader-Meunier B, et al. European consensus-based recommendations for the diagnosis and treatment of rare paediatric vasculitides-the SHARE initiative. Rheumatology. 2019;58(4):656-71.

34. Angeles-Han ST, Ringold S, Beukelman T, Lovell D, Cuello CA, Becker ML, et al. 2019 American College of Rheumatology/Arthritis Foundation guideline for the screening, monitoring, and treatment of juvenile idiopathic arthritis-associated uveitis. Arthritis Care Res. 2019;71(6):703-16.

35. Angeles-Han ST, Lo MS, Henderson LA, Lerman MA, Abramson L, Cooper AM, et al. Childhood Arthritis and Rheumatology Research Alliance consensus treatment plans for juvenile idiopathic arthritis-associated and idiopathic chronic anterior uveitis. Arthritis Care Res. 2019;71(4):482-91.

36. Fanouriakis A, Kostopoulou M, Alunno A, Aringer M, Bajema I, Boletis JN, et al. 2019 update of the EULAR recommendations for the management of systemic lupus erythematosus. Ann Rheum Dis. 2019;78(6):736-45.

37. Groot N, De Graeff N, Avcin T, Bader-Meunier B, Brogan P, Dolezalova P, et al. European evidence-based recommendations for diagnosis and treatment of childhood-onset systemic lupus erythematosus: the SHARE initiative. Ann Rheum Dis. 2017;76(11):1788-96.

38. Enders FB, Bader-Meunier B, Baildam E, Constantin T, Dolezalova P, Feldman $\mathrm{BM}$, et al. Consensus-based recommendations for the management of juvenile dermatomyositis. Ann Rheum Dis. 2017;76(2):329-40.

39. McCrindle BW, Rowley AH, Newburger JW, Burns JC, Bolger AF, Gewitz M, et al. Diagnosis, treatment, and long-term management of Kawasaki disease: a scientific statement for health professionals from the American Heart Association. Circulation. 2017;135(17):e927-99.

40. Ozen S, Demirkaya E, Erer B, Livneh A, Ben-Chetrit E, Giancane G, et al. EULAR recommendations for the management of familial Mediterranean fever. Ann Rheum Dis. 2016;75(4):644-51.

41. Ringold S, Angeles-Han ST, Beukelman T, Lovell D, Cuello CA, Becker ML, et al. 2019 American College of Rheumatology/Arthritis Foundation guideline for the treatment of juvenile idiopathic arthritis: therapeutic approaches for non-systemic polyarthritis, sacroiliitis, and enthesitis. Arthritis Care Res. 2019;71(6):717-34.

42. Ringold S, Weiss PF, Colbert RA, DeWitt EM, Lee T, Onel K, et al. Childhood Arthritis and Rheumatology Research Alliance consensus treatment plans for new-onset polyarticular juvenile idiopathic arthritis. Arthritis Care Res. 2014;66(7):1063-72.

43. Dewitt EM, Kimura Y, Beukelman T, Nigrovic PA, Onel K, Prahalad S, et al. Consensus treatment plans for new-onset systemic juvenile idiopathic arthritis. Arthritis Care Res. 2012;64(7):1001-10.

44. Mina R, Von Scheven E, Ardoin SP, Eberhard BA, Punaro M, llowite N, et al. Consensus treatment plans for induction therapy of newly diagnosed proliferative lupus nephritis in juvenile systemic lupus erythematosus. Arthritis Care Res. 2012;64(3):375-83.

45. Huber AM, Robinson AB, Reed AM, Abramson L, Bout-Tabaku S, Carrasco R, et al. Consensus treatments for moderate juvenile dermatomyositis: beyond the first two months. Results of the second Childhood Arthritis and Rheumatology Research Alliance consensus conference. Arthritis Care Res. 2012;64(4):546-53.

46. Zulian F, Culpo R, Sperotto F, Anton J, Avcin T, Baildam EM, et al. Consensus-based recommendations for the management of juvenile localised scleroderma. Ann Rheum Dis. 2019;78(8):1019-24.

47. Li SC, Torok KS, Pope E, Dedeoglu F, Hong S, Jacobe HT, et al. Development of consensus treatment plans for juvenile localized scleroderma: a roadmap toward comparative effectiveness studies in juvenile localized scleroderma. Arthritis Care Res. 2012;64(8):1175-85.

48. de Graeff N, Groot N, Ozen S, Eleftheriou D, Avcin T, Bader-Meunier B, et al. European consensus-based recommendations for the diagnosis and treatment of Kawasaki disease-the SHARE initiative. Rheumatology. 2019; 58(4):672-82. 
49. Ter Haar NM, Oswald M, Jeyaratnam J, Anton J, Barron KS, Brogan PA, et al. Recommendations for the management of autoinflammatory diseases. Ann Rheum Dis. 2015;74(9):1636-44.

50. Zhao Y, Wu EY, Oliver MS, Cooper AM, Basiaga ML, Vora SS, et al. Consensus Treatment Plans for Chronic Nonbacterial Osteomyelitis Refractory to Nonsteroidal Antiinflammatory Drugs and/or With Active Spinal Lesions. Arthritis Care Res. 2018;70(8):1228-37.

51. Groot N, De Graeff N, Marks SD, Brogan P, Avcin T, Bader-Meunier B, et al. European evidence-based recommendations for the diagnosis and treatment of childhood-onset lupus nephritis: the SHARE initiative. Ann Rheum Dis. 2017;76(12):1965-73.

52. McGeoch L, Twilt M, Famorca L, Bakowsky V, Barra L, Benseler S, et al. CanVasc recommendations for the management of antineutrophil cytoplasm antibody (ANCA)-associated vasculitides-Executive summary. Can J kidney Heal Dis. 2015:2(1):43.

53. Rohekar S, Chan J, Shirley ML, Haroon N, Chandran V, Bessette L, et al. 2014 Update of the Canadian Rheumatology Association/Spondyloarthritis Research Consortium of Canada treatment recommendations for the management of spondyloarthritis. Part II: specific management recommendations. J Rheumatol. 2015;42(4):665-81.

54. Singh JA, Guyatt G, Ogdie A, Gladman DD, Deal C, Deodhar A, et al. 2018 American College of Rheumatology/National Psoriasis Foundation guideline for the treatment of psoriatic arthritis. Arthritis Rheum. 2019;71(1):5-32.

\section{Publisher's Note}

Springer Nature remains neutral with regard to jurisdictional claims in published maps and institutional affiliations.

Ready to submit your research? Choose BMC and benefit from:

- fast, convenient online submission

- thorough peer review by experienced researchers in your field

- rapid publication on acceptance

- support for research data, including large and complex data types

- gold Open Access which fosters wider collaboration and increased citations

- maximum visibility for your research: over $100 \mathrm{M}$ website views per year

At $\mathrm{BMC}$, research is always in progress.

Learn more biomedcentral.com/submissions 